\title{
Evaluation of Brey's production/biomass model on the basis of a long-term data set on a clam population
}

\author{
J. J. Beukema*, R. Dekker \\ NIOZ Royal Netherlands Institute for Sea Research, PO Box 59, 1790 AB Den Burg, Texel, The Netherlands
}

\begin{abstract}
The Brey model is one of the most frequently used methods to obtain a quick estimate of the secondary production $(P)$ of an area. It is based on an empirical relationship between the production/biomass $(P / B)$ ratio and the (annual) mean weight $(W)$ of the individuals of a population. Estimates of $P / B$ by this model are frequently obtained by using only single measurements of $W$ and $B$, thus circumventing tedious efforts required by conventional methods. The obtained $P$ values of communities are sums of estimates made for individual species. Any constraints of the model can be fully understood only by evaluating it for single-species populations. Using an extensive data set obtained by monitoring a population of the bivalve Macoma balthica for $33 \mathrm{yr}$, we evaluated the model by comparing Brey model estimates of $P$ and $P / B$ with direct annual estimates. We corroborate the basis of the model by presenting a significant relationship between observed annual values of $W$ and $P / B$. The model satisfactorily predicted $P$ when late-winter (but not late-summer) assessments of $W$ and $B$ were used. The model underestimated $P / B$ in the years with high mortality rates $(Z)$, whereas it overestimated $P / B$ in almost all other years. $Z$ values were a better basis for predictions of $P / B$ than $W$ values. The model could predict $P / B$ well on the exclusive basis of $W$ due to the significant correlation between $W$ and $Z$ (low $Z$ values resulted in older and thus heavier individuals). Multi-year averages of model-predicted and observed $P / B$ estimates were similar only when predictions were based on late-winter or annual (not on summer) estimates of $W$ and $B$. In conclusion, the model cannot be recommended for precise and unbiased $P$ estimates in a single species when no more than a once-only assessment of $W$ and $B$ is available.
\end{abstract}

KEY WORDS: Biomass $\cdot$ Secondary production $\cdot$ Individual weight $\cdot$ Mortality rate $\cdot$ Macoma balthica $\cdot$ Bivalve $\cdot$ Wadden Sea $\cdot$ Tidal flats $\cdot$ Long-term data series

\section{INTRODUCTION}

An assessment of the annual production of a population or a community is a time-consuming endeavor that involves the collection of a long series of data on numbers and weights of individuals. To avoid this laborious task of obtaining a series of growth and/or survival estimates on populations, it is tempting to simply calculate production $(P)$ from much easier obtainable values of biomass $(B)$ by application of published or estimated production/biomass $(P / B)$ ratio values. Several examples of the use of such a short-cut procedure for marine benthos were published in recent years, including Reiss et al. (2009), Neumann et al. (2009), Bolam et al. (2010, 2011), Wong et al. (2011) and Kedra et al. (2013). However, the accuracy and possible bias of the estimates of $P$ obtained in this way are virtually unknown and appear to have been evaluated only rarely. Notable exceptions are the evaluations for 3 species by Mistri et al. (2001) and for 5 species by Dolbeth et al. (2005), and the worldwide reviews by Cusson \& Bourget (2005) and Petracco et al. (2012). 
By collating data of $>1000$ populations of a wide range of invertebrate species, Brey $(1990,1999,2001)$ empirically established relationships between $P / B$ and mean individual weight, $W$ (a logarithmic relationship) and between $P / B$ and annual instantaneous rate of mortality, $Z$ (a linear relationship: $P / B=Z$ ). Estimation of $Z$ as a time-saving shortcut to estimation of $P / B$ is not a real help, as assessments of mortality rates involve laborious collection of series of data on numerical densities. Robertson (1979) proposed the use of life span, which declines with increasing $Z$. From a review of available data for marine macrozoobenthos, he found the expected negative relationship between $P / B$ and life span. However, the usefulness of life span as a predictor of $P / B$ is limited, because estimates of life span depend, among other factors, on the accuracy of age determinations and the applicability of a literature-derived longevity estimate (mostly from a different population) for the population studied. Furthermore, life span is an ill-defined parameter that is biased by research effort: the more individuals are aged, the higher the chance of encountering an older specimen (Beukema 1989).

The relationship between $P / B$ and $W$ (Brey 1990) offers a real shortcut for the prediction of $P / B$. Species or populations that are characterized by relatively small individuals with relatively low individual weights show relatively high values of $Z$ and $P / B$. It has been proposed that the relationship between $P / B$ values and body weight can be assessed using maximal weight (Tumbiolo \& Downing 1994), weight on reaching maturity (Banse \& Mosher 1980) or mean weight of all individuals within the population (Schwinghamer et al. 1986, Brey 1990, 2001). Again, there are some limitations: (1) estimates of maximal body weight suffer from the same possible bias as those of life span; (2) the exact time of reaching maturity may be somewhat arbitrary; and (3) estimates of weights or ages obtained from the published literature may not be fully representative for the population studied. In the following, we limit our appraisal to the mean-individual-weight method proposed by Brey (2001) for 2 reasons: (1) the Brey model is now used more frequently than other models, and (2) it performed better than any other empirical model for the prediction of $P / B$ or $P$ values in tests by Cusson \& Bourget (2005) and Dolbeth et al. (2005). On the other hand, Mistri et al. (2001) found the predictions of $P$ by the method proposed by Tumbiolo \& Downing (1994) superior to those by other indirect methods, but this model proved to be the worst performing one in the test by Cusson \& Bourget (2005).
The aim of the present study was to evaluate the Brey (2001) model for a specific population of a macrozoobenthic species: Macoma balthica (L.), which was monitored for a long period in an extensive intertidal Wadden Sea area. Though the Brey $(1990,2001)$ model is based on (mostly) annual estimates of the population parameters $W$ and $B$, it has frequently been used to estimate annual $P$ from a single assessment of these 2 parameters. In logarithmic form, the relationship Brey found was linear and approximated $\log P / B=-0.5-0.25 \log W$. The exact magnitudes of the included term of about -0.5 and factor of about -0.25 depend on such factors as temperature, depth and group of animals concerned (see Brey 2001). Figures reported in the literature for the exponent of $W$ are usually within the range -0.25 to -0.33 , but there is an insufficient theoretical basis for adopting a fixed value (Van der Meer 1998), such as proposed by Sprung (1993) and Roa \& Quinones (1998). Because the above relationship between $P / B$ and $W$ is an empirical one, and thus is a best fit of data representing several populations of many different species, data of any single population would not exactly match the relationship. Brey (1990) was aware of this limitation and recommended the use of his method only for communities with at least 5 species. Nevertheless, we considered it a worthwhile exercise to evaluate this model for a population of a single species. We aimed to better understand (1) why values of $W$ can provide fair estimates of $P / B_{1}(2)$ how precise these estimates are, and (3) whether differences between Brey estimates and actual $P$ or $P / B$ values can be predicted. In essence, Brey estimates of $P$ for a community are sums of a number of singlespecies estimates. Therefore, we think that a full understanding of the Brey model should start with detailed single-species studies. For instance, if Brey estimates for single species were biased in similar ways, their sums would be.

To this end, we explored to what extent our data set on the bivalve Macoma balthica on Balgzand (Dekker \& Beukema 2007) fitted the above equation (after its adaptation to bivalves on tidal flats in the western Wadden Sea) and under what conditions the observed $P$ and $P / B$ values deviated from values predicted by the model. The available data set included 33 twice-annual values of numerical density, recruitment, mortality rate, biomass, mean individual weight and production (Dekker \& Beukema 2007). All estimated population parameters, including mean individual weights, varied substantially among years (e.g. Beukema et al. 2009). Therefore, Brey-estimated $P / B$ values ranged widely and these model- 
calculated values were compared with observed annual $P / B$ ratio values.

\section{MATERIALS AND METHODS}

\section{Data collection}

Since the 1970s, the macrozoobenthos community has been monitored at 15 fixed sampling sites at a $50 \mathrm{~km}^{2}$ tidal-flat area called Balgzand in the westernmost part of the Dutch Wadden Sea (at about $53^{\circ} \mathrm{N}$ and $5^{\circ} \mathrm{E}$ ). The monitoring program comprised twiceannual (late-winter: mostly March, and late-summer: mostly August) estimates of numbers and biomass of all macrobenthic (retained on $1 \mathrm{~mm}$ sieves) animal species. We used the data on Macoma balthica collected for a period of $33 \mathrm{yr}$ (1978 to 2010). The sampling sites were scattered (almost) randomly over the Balgzand area. The individual sites differed in elevation (relative to mean sea level) and sediment composition. Together they covered the entire intertidal depth range and all sediment types. Because of the (nearly) random distribution of the sampling sites over the area, the 15 site averages may be considered as fair estimates for the entire Balgzand population. Details on sampling sites and methods can be found in earlier publications (e.g. Beukema \& Cadée 1997).

Abundance is expressed in ind. $\mathrm{m}^{-2}, B$ in $\mathrm{g}$ ash-free dry mass (AFDM) $\mathrm{m}^{-2}$ and $P$ in $\mathrm{g}$ AFDM m $\mathrm{m}^{-2} \mathrm{yr}^{-1}$. All Macoma balthica were sorted from the sieved samples, measured and opened by short immersion in boiling water to remove the soft parts. These were dried ( 2 or $3 \mathrm{~d}$ at $60^{\circ} \mathrm{C}$ in a ventilated stove), weighed (individually or per $1 \mathrm{~mm}$ shell-length class) and incinerated. AFDM is dry weight minus ash weight. The shells were assigned to age classes by external examination of the number of year marks on the shell, following Lammens (1967). We are confident that the marks read were truly annual, because strong cohorts could easily be traced as peaks in the length-frequency distributions for several years after their appearance.

\section{Estimation of production}

For assessments of actual values of somatic $P$, we chose the weight-increment summation method as described by Van der Meer et al. (2005), using weight increments (or diminutions) between 2 sampling times per year: in late winter at minimal seasonal values of individual weight and biomass and in late summer at maximal values. For each half-year period and each age class, and at each of the 15 sites, separate $P$ values were estimated by multiplication of the mean $\mathrm{N}$ over the period by the change in $W$ during that period. The age-class estimates were added to obtain population estimates for each of the 15 individual sampling sites. In the present paper, we only report averages of the 15 separate site values to represent Balgzand-population $P$ estimates. Annual net production represents the March to March period and is the sum of 2 successive seasonal estimates, i.e. March to August (growing season with mostly positive values) and August to March (weight-loss season with mostly negative values). More detailed production data can be found in Dekker \& Beukema (2007).

This method of assessing annual production by summing seasonal production estimates is superior to calculations using only once-per-year estimates of numbers and individual weights (as explained by Dekker \& Beukema 2007). Sampling more frequently than twice annually would certainly have resulted in more precise estimates of annual $P$, as shown in a simulation study by Cusson et al. (2006). They showed that both bias as well as random errors declined with sampling frequency. More frequent sampling proved to be not practical for a long-term field study (lasting for decades) with several sampling sites. A further limitation of our study was that we did not succeed in estimating production of spat-sized animals (see Dekker \& Beukema 2007). Therefore, all estimates (of $P, \mathrm{~N}, B, W$ and $Z$ ) refer to individuals that are at least $\sim 0.9$ yr old (having survived their first winter).

In addition to the $W$ values observed in March and August, we calculated annual $W$ values for all individuals $>0.9$ yr old as the averages of mean individual weights of these individuals during the growing season (means of March and August values) and the weight loss season (means of August and subsequent March values), thus as $0.25 \times($ March mean weight + $[2 \times$ August mean weight $]+$ subsequent March mean weight).

\section{The Brey model}

We simplified the multi-parameter model (version 4-04) of Brey (2001) to $\log P / B=-0.205-0.238 \log M$ (in which $M$ is mean individual weight expressed in $\mathrm{kJ}$ ). Because we prefer weight units, we converted the above equation to $\log P / B=-0.52-0.238 \log W$, in which $W$ is mean individual weight expressed in $g$ AFDM, using $1 \mathrm{~g}$ AFDM $=23 \mathrm{~kJ}$, according to Beukema (1997). To apply to an intertidal infaunal 
bivalve population in the western Wadden Sea, where the mean annual water temperature is $10.5^{\circ} \mathrm{C}$ (Van Aken 2008), we filled in the following factors: water depth, $D=1$, subtidal SubT $=0$, infauna In-Epi $=1$, motile MoEpi $=0$, Taxon $1=0, \operatorname{Taxon} 2=0$, Taxon $3=0$, Habitat $1=0$ and temperature, $T=10.5$.

We did not use the recent artificial neural network model approach by Brey (2012) because inclusion of this model version would add little to the present analysis. According to Brey (pers. comm.), the new model is subject to the same constraints as the older ones for a 1-species analysis and is not expected to yield 'better' results. The artificial neural network approach showed an only slightly better performance in predicting $P / B$ for communities (Brey et al. 1996).

For the Balgzand Macoma balthica population, we calculated $P / B$ ratio values according to the Brey (2001) model (version 4-04) for each of 32 years (1978 to 2010, but omitting 1988). For each of these years, we separately calculated $2 P / B$ ratio values, namely for the $W$ values observed in March and August. These sets of Brey-estimated $P / B$ values were multiplied by the corresponding observed March and August values of $B$ to obtain for each year 2 modelbased estimates of $P$, one entirely based on the March observations of $W$ and $B$, the other on the August observations of these parameters. By using only data from a single sampling occasion (either March or August) for the Brey-model estimates, rather than available annual mean values of $B$ and $W$, we mimicked the procedure generally followed by users of the Brey model.

\section{Statistics}

Statistical tests were used to indicate levels of significance of observed relationships. We used Pearson correlation values for relationships between nontransformed data. Generally, frequency distributions of these data were close to normal. In cases of doubt, we checked p-values by the non-parametric Spearman rank correlation test.

\section{RESULTS}

\section{Long-term data series on the studied population}

During the 33 years of the 1978 to 2010 period of observation, the population of Macoma balthica on Balgzand was far from constant and showed both substantial year-to-year variability as well as significant long-term trends (Fig. 1). We do not show standard errors in Fig. 1, because these would represent only the substantial (but consistent from year to year) differences between the 15 sites. The intention of Fig. 1 is to show interannual variation of the various estimates for the Balgzand area as a whole.

Numerical densities (Fig. 1A), $B$ (Fig. 1B) and annual $P$ (Fig. 1C) tended to increase more or less regularly until the late 1980s or early 1990s, and then decrease to reach low values in the late 2000s. These trends run parallel at all sampling sites. The conspicuous downward trend of recent years can be explained by the consistently low levels of annual recruitment after 1991 (Beukema et al. 2009) and the enhanced mortality rates that occurred for a $7 \mathrm{yr}$ period around 2000 (Fig. 1F). Mean weights were reduced during the period of high mortality and some subsequent years (Fig. 1E). They fluctuated around $0.04 \mathrm{~g}$ AFDM ind. ${ }^{-1}$ until the mid-1990s, and around $0.025 \mathrm{~g}$ AFDM ind. ${ }^{-1}$ afterwards, only returning to the original level in 2010.

Until the late 1990s, the observed annual $P / B$ ratio values (Fig. 1D) were relatively constant, fluctuating mostly within the range of 0.3 to $0.7 \mathrm{yr}^{-1}$. These values occurred at production levels ranging mostly between 1 and $3 \mathrm{~g}$ AFDM $\mathrm{m}^{-2} \mathrm{yr}^{-1}$ (Fig. 1C). However, in most of the more recent years, and particularly during the 7 years with high mortality (1999 to 2005), $P / B$ values were elevated, with several values exceeding $0.7 \mathrm{yr}^{-1}$ (Fig. 1D). Such high ratio values were rarely reached before 1999. The elevated ratio values for the 1999 to 2005 period occurred at much lower levels of $P$ than in the foregoing period: $\leq 1$ instead of $\sim 2 \mathrm{~g}$ AFDM m $\mathrm{m}^{-2} \mathrm{yr}^{-1}$ (compare Fig. 1C). Thus, the high $P / B$ values observed during this period were not due to high $P$ (see Fig. 1C) but to very low $B$ values (see Fig. 1B).

The extremely low $P / B$ value of $<0.2 \mathrm{yr}^{-1}$ in 1988 was considered an outlier. It was so low because of an exceptionally low (relative to $B$ ) estimate of $P$ in that year (Fig. 1C), caused by strong individual weight losses of adult Macoma balthica in the 1988 to 1989 winter half-year. In the following, the values of $P$ and $P / B$ for 1988 are omitted. For the remaining 32 years, the long-term mean of observed $P / B$ values $( \pm \mathrm{SE})$ amounted to $0.62 \pm 0.04 \mathrm{yr}^{-1}$.

There was a clear connection between annual $Z$ and annual $P / B$ ratio values: note the similarity of the long-term patterns in Fig. 1D,F. These patterns were more or less mirrored in Fig. 1E showing $W$. In 

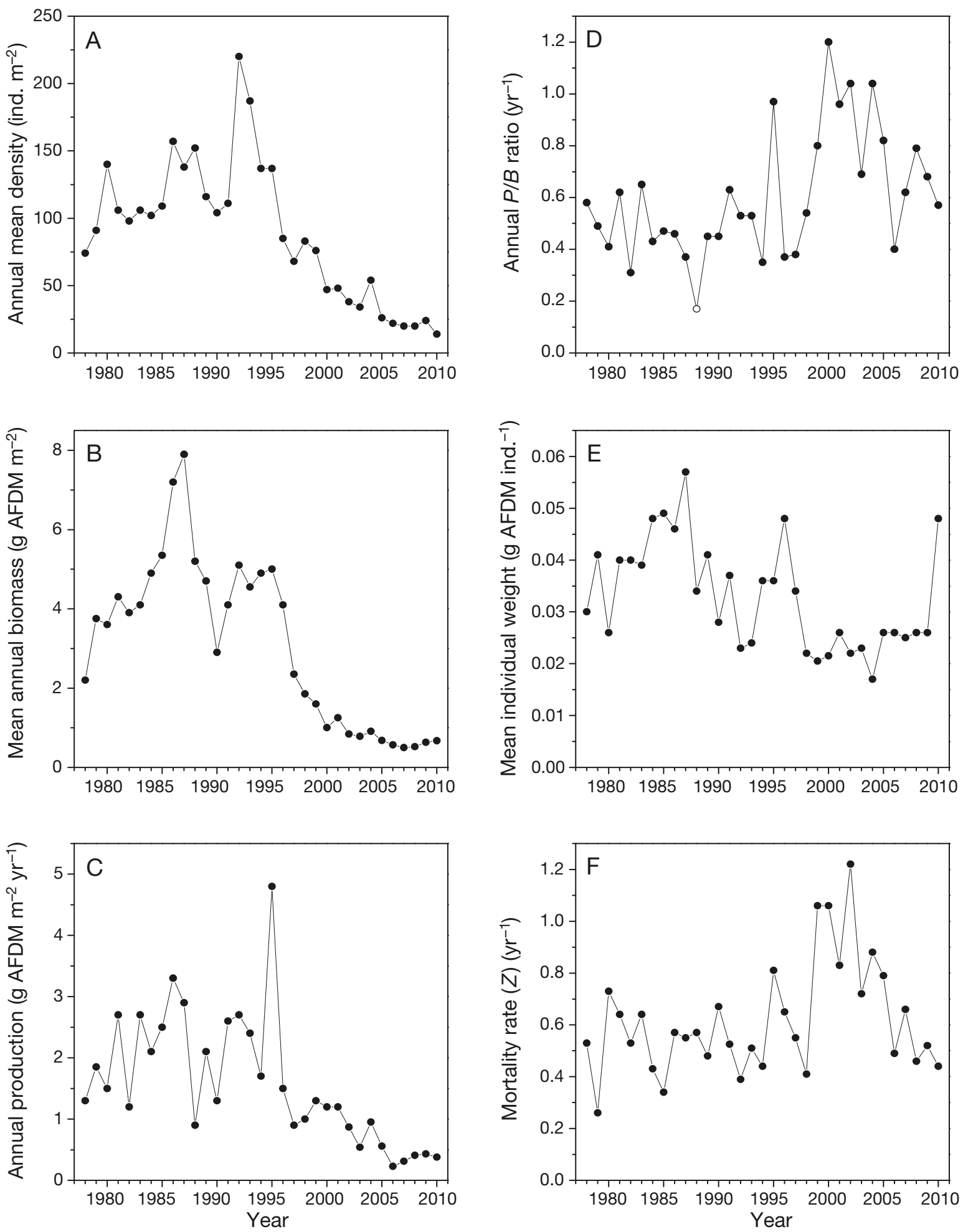

Fig. 1. Macoma balthica. Long-term (1978 to 2010) data series of annual means or totals on the population on Balgzand based on results of twice-annual sampling at 15 permanent sites in March and August, excluding data on spat-sized animals found in August. (A) Annual mean numerical densities; averages of the 2 half-year estimates (March to August and August to March periods). (B) Annual mean biomass $(B)$ of soft parts. (C) Total annual soft-part somatic production $(P)$. (D) Annual $P / B$ ratios; the $P / B$ value for 1988 (open point) was considered an outlier. (E) Annual mean weight per individual (W). (F) Annual instantaneous rates of mortality (ln total no of ind. in March / total no of ind. belonging to the same cohorts that were still alive 1 yr later). AFDM = ash-free dry mass 

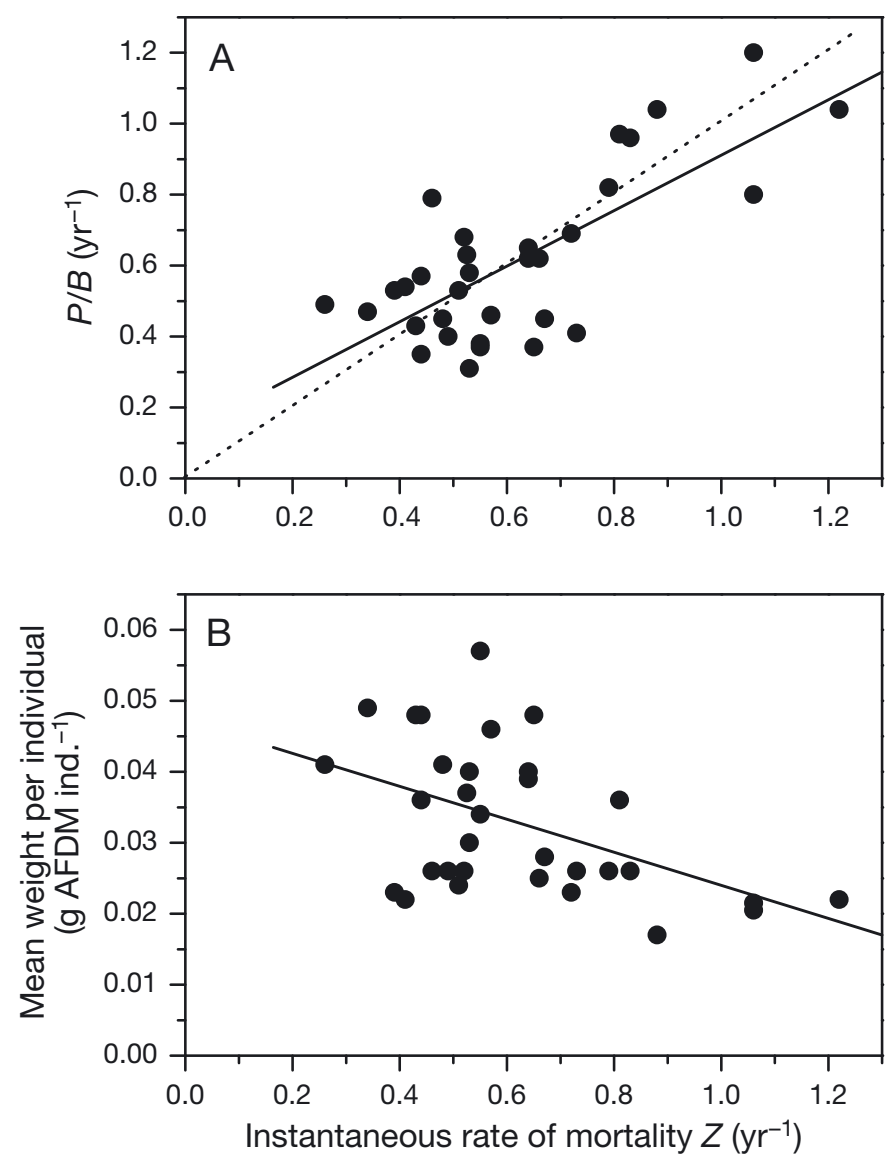

Fig. 2. Macoma balthica. Relationships between observed annual values of instantaneous rates of mortality and (A) observed annual production/biomass $(P / B)$ ratio values and (B) observed mean individual weights $(W)$. Data taken from Fig. 1. The theoretically expected 1:1 ratio for a balanced population is indicated in (A) by a dotted line. Best linear fits: for $(\mathrm{A}), P / B=0.13+0.78 Z(\mathrm{n}=32$, Pearson $\mathrm{r}=0.74$, $\mathrm{p}<0.0001)$; for $(\mathrm{B}), W=0.047-0.023 Z(\mathrm{n}=33$, Pearson

$$
\mathrm{r}=-0.48, \mathrm{p}<0.01)
$$

Fig. 2, we present correlations between the annual values of 3 parameters $(Z, P / B$ and $W)$ of the Macoma balthica population. The observed annual values of $P / B$ showed a statistically highly significant positive linear relationship with annual values of $Z$ (Fig. 2A). The best linear fit was close to a 1:1 relationship (dotted line in Fig. 2A): intercept and slope were not significantly different from 0.0 and 1.0 , respectively ( $\mathrm{p}>0.05$, t-tests). $W$ declined significantly (Fig. 2B: p < 0.01, t-test) with increasing values of $Z$. Thus, on average, lower values of $W$ were bound to coincide with higher values of $P / B$, as both occurred at particularly high values of $Z$. Such a relationship between $W$ and $P / B$ is a precondition of the Brey model and was fulfilled (see Fig. $4 ; \mathrm{p}<0.001, \mathrm{n}=32$ ).
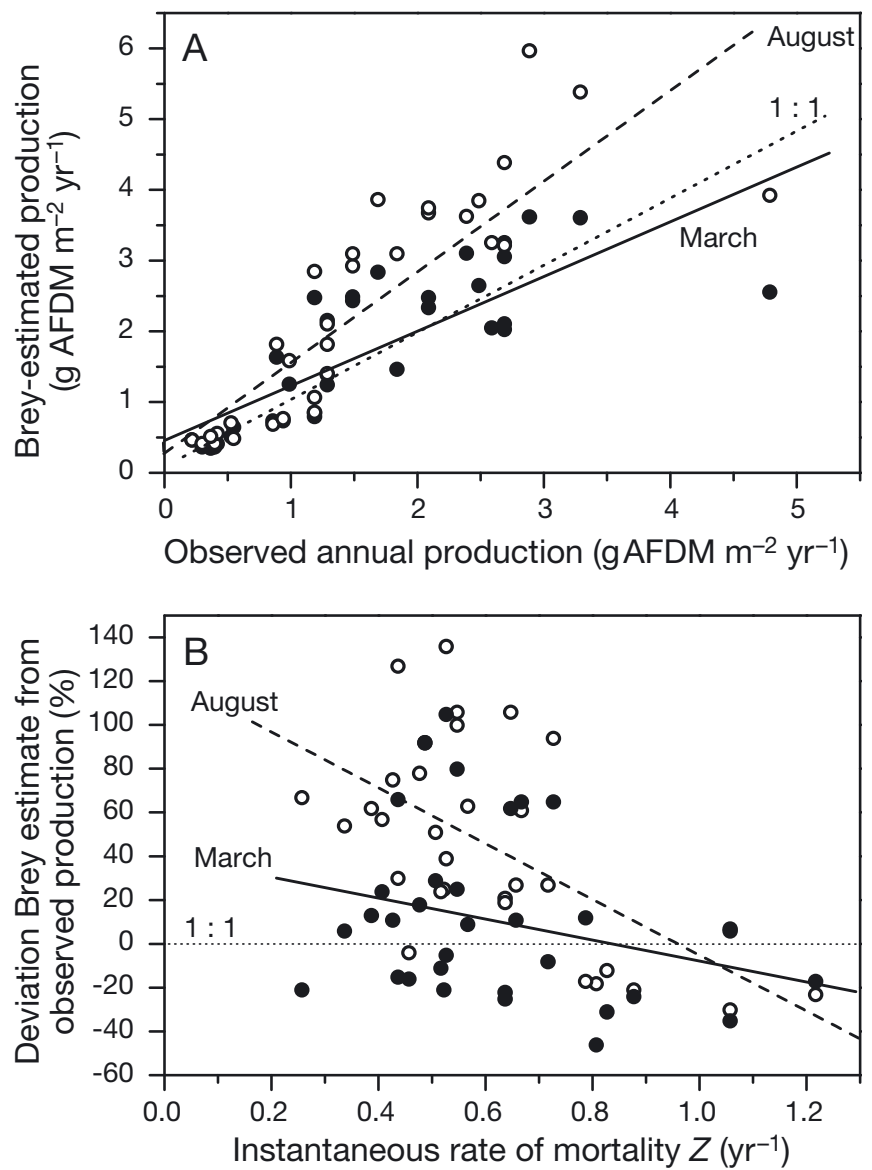

Fig. 3. Macoma balthica. (A) Comparisons between observed $\left(P_{\text {obs }}\right)$ and Brey-estimated $\left(P_{\text {brey }}\right)$ values for annual production $(P)$. Best linear fits: August data (dashed line) $P_{\text {brey }}=0.27+1.29 P_{\text {obs }}, \mathrm{n}=32$, Pearson $\mathrm{r}=0.85, \mathrm{p}<0.0001$; March data (solid line) $P_{\text {brey }}=0.46+0.77 P_{\text {obs }}, \mathrm{n}=32$, Pearson $\mathrm{r}=0.77, \mathrm{p}<0.0001$. (B) Relationships between the deviation $(D)$ of Brey estimates from observed values (expressed as \% of the observed values) and mortality rate in the same year (as instantaneous annual rates, $Z$, from Fig. 1F). Best linear fits: for August data (open points, dashed line), $D=$ $122-127 Z, \mathrm{n}=32$, Pearson $\mathrm{r}=-0.60, \mathrm{p}<0.0001$; for March data (solid points, solid line), $D=42-49 Z, \mathrm{n}=32$, Pearson $\mathrm{r}=-0.27, \mathrm{p}>0.1$

\section{Comparison of Brey estimates of $\boldsymbol{P}$ with observed values}

The 2 sets of model-calculated values of $P$ (Fig. 3A) were positively correlated with the observed annual values (August: Pearson $\mathrm{r}=0.85, \mathrm{n}=32, \mathrm{p}<0.0001$; March: $\mathrm{r}=0.77, \mathrm{n}=32, \mathrm{p}<0.0001)$. The Brey-estimated values followed similar long-term patterns as shown in Fig. 1C for the directly observed values: an initial period of $\sim 20$ yr characterized by an increasing trend and a consistently declining trend since around 1995. The model-calculated values of $P$ that were 


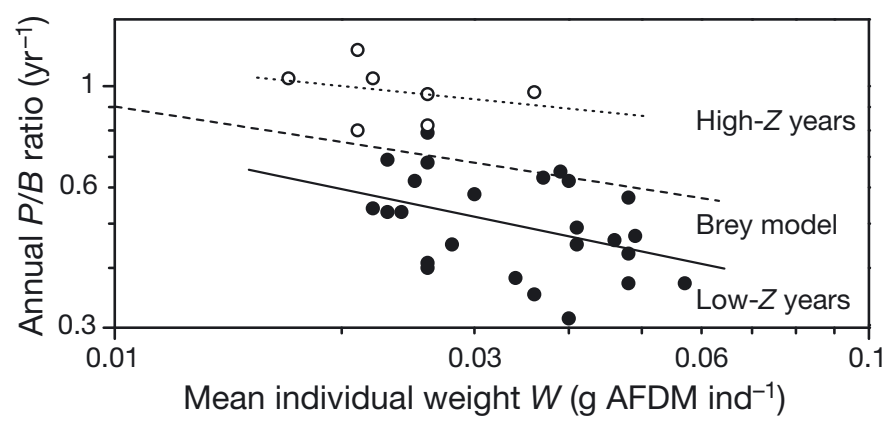

Fig. 4. Macoma balthica. Relationships on a log-log scale between observed annual values of individual mean weight and production/biomass $(P / B)$ ratio for observed values (open and solid points; data taken from Fig. 1E,D) and according to the Brey (2001) model (dashed line). The observed values are presented in 2 groups: the 7 years with high mortality $\left(Z>0.75 \mathrm{yr}^{-1}\right.$; open points) and the 25 remaining years with lower mortality (solid points). Best linear fits: for high-mortality years (dotted line), $\log P / B=-0.24-$ $0.15 \log W(\mathrm{n}=7$, Pearson $\mathrm{r}=-0.24, \mathrm{p}>0.1)$; for lowermortality years (solid line), $\log P / B=-0.81-0.34 \log W$ $(\mathrm{n}=25$, Pearson $\mathrm{r}=-0.41, \mathrm{p}<0.05)$

based on March observations of $W$ and $B$ did not differ consistently from the directly observed annual values (solid points and full line in Fig. 3A). On average, the estimated and observed values amounted to $1.70 \pm 0.18$ and $1.61 \pm 0.19 \mathrm{~g} \mathrm{AFDM} \mathrm{m}^{-2} \mathrm{yr}^{-1}$, respectively (32 yr mean $\pm \mathrm{SE}$ ). The mean deviation amounted to $0.09 \pm 0.12 \mathrm{~g} \mathrm{AFDM} \mathrm{m}^{-2} \mathrm{yr}^{-1}$ and this difference between calculated and observed values of $<10 \%$ was statistically non-significant $(t$-test and sign test: the Brey model values of $P$ were higher than the directly observed values in 18 and lower in 14 years).

The Brey model estimates of $P$ that were based on August observations of $W$ and $B$ differed more from the observed annual values and positive deviations were significantly more frequent than underestimates ( 27 versus 5 years, $\mathrm{p}<0.01$, sign test). The long-term mean of $2.34 \pm 0.28 \mathrm{~g} \mathrm{AFDM} \mathrm{m}^{-2} \mathrm{yr}^{-1}$ was substantially (almost $50 \%$ ) and statistically significantly higher than the long-term mean of observed values of $1.61 \mathrm{~g} \mathrm{AFDM} \mathrm{m}^{-2} \mathrm{yr}^{-1}$. The mean deviation amounted to $0.74 \pm 0.16 \mathrm{~g} \mathrm{AFDM} \mathrm{m}^{-2} \mathrm{yr}^{-1}$. In 28 years, the Brey estimates that were based on August data were higher, and in only 4 years they were lower than the Brey estimates that were based on March data ( $p<0.001$, sign test). On average, August estimates were 2.34/1.70 = 1.38 times higher than March estimates. This difference arose mainly from the onaverage 1.67 times higher biomass values observed in August than in March and was only partly compensated by the slightly lower means of Brey- estimated $P / B$ values that were based on mean individual weights in August and March: 0.63 and 0.76 $\mathrm{yr}^{-1}$, respectively.

Expressed as a proportion of the observed values for the same years, the deviations of the Brey estimates for $P$ from observed annual values ranged from -47 to 104 (mean $12 \pm 7 \%$ ) for estimates based on March observations and from -31 to 135 (mean $44 \pm 8 \%$ ) for those based on August observations (Fig. 3B). Thus, underestimates by the Brey method amounting to less than half of the observed values did not occur, but overestimates of $>50 \%$ were frequent, especially for August data, viz. in 15 out of the 32 years (March data: 7 out of the 32 years). Even overestimates of $P$ exceeding $100 \%$ occurred, particularly when August data were used.

The Brey model overestimated $P$ particularly in years characterized by low $Z$ values, whereas underestimates were relatively frequent in years with high values of $Z$ (Fig. 3B). For the estimates based on August observations of $B$ and $W$ (open points and dashed line in Fig. 3B), the negative linear relationship between the deviations from observed values and $Z$ was statistically significant (Pearson $\mathrm{r}=-0.60$, $\mathrm{n}=32, \mathrm{p}<0.001$ ). For the March data, the relationship was also negative, but non-significant $(\mathrm{r}=-0.27$, $\mathrm{n}=32, \mathrm{p}>0.1$ ). Note in Fig. 3B that for the August data the rare underestimates by the Brey model were nearly restricted to the few years with exceptionally high values of $Z\left(>0.75 \mathrm{yr}^{-1}\right)$.

\section{Reliability of $P / B$ estimates from data on individual weights}

The basic assumption of the Brey model is the negative relationship between $P / B$ and $W$, being linear on a log scale. This relationship as described by Brey (2001) is depicted by a dashed line in Fig. $4: \log P / B=$ $-0.52-0.24 \log W$. In the following, we studied the relationship between observed annual mean values of $W$ and $P / B$ and no longer used seasonal values of $W$ and $B$ (as we did in Fig. 3 to mimic the usual procedures by users of the Brey model). The annual values of $P, W$ and $B$ were derived from seasonal data as described in 'Materials and methods'.

We found a significantly negative relationship between observed annual means of $W$ and observed values of $P / B$ of the same year (Pearson $r=-0.59$, Spearman $\mathrm{r}=-0.58, \mathrm{n}=32, \mathrm{p}<0.001$ ). However, the observed values did not strictly follow the model: the decline of $P / B$ with increasing $W$ was significantly steeper in the Macoma balthica population than in 

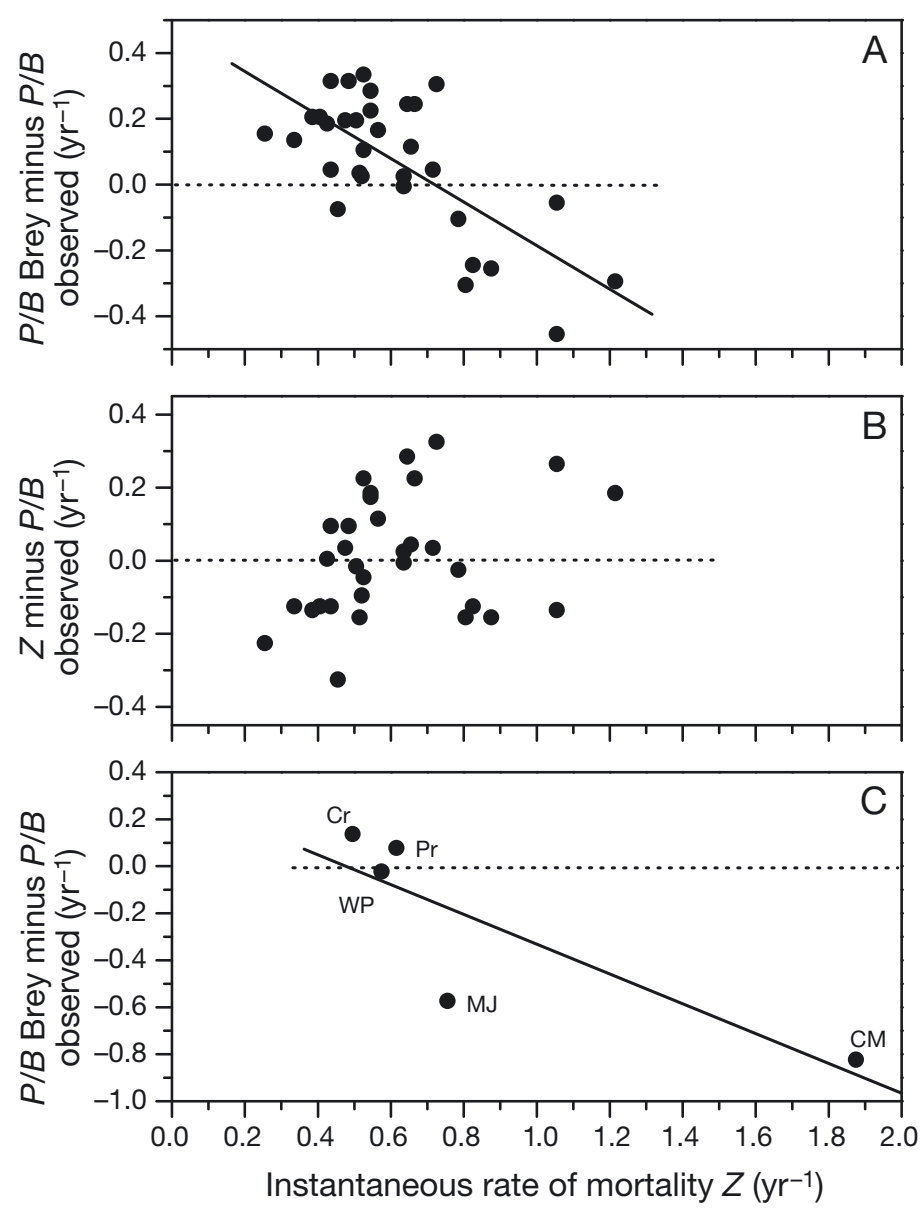

Fig. 5. Macoma balthica; animals $>0.9$ yr old. (A) Deviations of Brey model estimates from observed $P / B$ values in the Balgzand population. Data for $Z$ from Fig. 1F. Best linear fit: $D=0.48-0.66 Z$ (Pearson $\mathrm{r}=-0.70, \mathrm{n}=32, \mathrm{p}<0.0001$ ). (B) Differences between observed values of $Z$ and $P / B$ in the Balgzand population. Data from Fig. 1D,F. (C) Deviations of Brey model estimates from observed $P / B$ values in various populations. $\mathrm{CM}=$ Chambers \& Milne (1975) on 1 population studied for $1 \mathrm{yr}$; WP = Warwick \& Price (1975) on 1 population studied for $1 \mathrm{yr} ; \mathrm{Cr}=$ Cranford et al. (1985) on mean of 5 populations studied for almost $1 \mathrm{yr}$; MJ = Madsen \& Jensen (1987) on mean of 2 populations studied for $1 \mathrm{yr}$; $\mathrm{Pr}=$ present study on mean of 15 sub-populations studied for $32 \mathrm{yr}$

the Brey model. At low $W$ values, observed $P / B$ values were higher than the model estimates, and at high $W$ values they were mostly lower (Fig. 4).

As stated above, in theory for balanced populations (and confirmed in practice for the present population; Fig. 2A), $P / B$ values are close to $Z$. Therefore, it makes sense to separately indicate the years with aberrantly high $Z$ values: the open points in Fig. 4 . No less than 6 of the 7 years with $Z>0.75 \mathrm{yr}^{-1}$ occurred in the 1999 to 2005 period (compare Fig. 1F). In all of these years with elevated $Z$ values, observed $P / B$ val- ues (open points in Fig. 4) were higher than the Brey estimates (which were based on $W$ ). On the other hand, nearly all of the observed $P / B$ values for the other 25 years (with less aberrant $Z$ values) were lower than the Brey model estimates for these years: nearly all of the solid points in Fig. 4 were situated below the Brey model line. Note in Fig. 4 that the best-fit lines for the 2 sets of observations as well as Brey model estimates run more or less in parallel, their different levels being determined by different mortality rates.

An obvious conclusion is that the Brey model would yield correct predictions of $P / B$ exclusively if $Z$ values were within a certain range - somewhere between 'high' and 'low'. Close-to-nil differences between Brey-predicted and observed $P / B$ values indeed occurred in some years with intermediate $Z$ values of between $\sim 0.4$ and $0.7 \mathrm{yr}^{-1}$ (Fig. 5A). On average, the departures of Brey values from reality were nil at a $Z$ value of $\sim 0.7 \mathrm{yr}^{-1}$ (from best-fitting linear relationship in Fig. 5A). For years with such rates of mortality, the chances of finding either over- or underestimates of $P / B$ by the Brey model roughly balanced. When mortality rates were lower, $W$ became higher (because mean ages and thus weights rise at low mortality) and accordingly Brey-predicted $P / B$ values became lower, but not to a sufficient extent (Fig. 4), resulting in overestimates by the model of $P / B$ and $P$ for years with low mortality (Fig. 5A). At higher mortality rates, the reverse was true. Only within a limited range of intermediate mortality rates did the Brey model yield (on average) unbiased estimates.

The long-term average of the deviations of Breypredicted $P / B$ estimates (calculated on the base of annual means of $W$ and $B$ ) from observed annual $P / B$ values shown in Fig. 5A amounted to $0.07 \pm 0.04 \mathrm{yr}^{-1}$ $(\mathrm{n}=32)$ and this mean did not significantly differ from 0 . The reason why this mean deviation was so small (amounting to only about $11 \%$ of the long-term mean of observed $P / B$ values of $0.62 \mathrm{yr}^{-1}$ ) was that positive and negative values in Fig. 5A roughly balanced. For single years, however, differences of $>0.3 \mathrm{yr}^{-1}$ (or $>50 \%$ of the long-term $P / B$ mean) were frequently found: in 8 of the 32 years. When the 32 deviations were weighed irrespective of the + or sign, they averaged to a substantial $0.18 \pm 0.02 \mathrm{yr}^{-1}$ or to $35 \pm 5 \%$ of the observed values, both mean values differing significantly from 0 ( $\mathrm{p}<0.001, t$-test).

As shown above (Fig. 2A), observed annual $P / B$ ratio values were closely related to the values of $Z$ in the same year. The long-term means of the $32 \mathrm{ob}-$ served values of $Z$ and $P / B$ hardly differed-the 
mean of the differences shown in Fig. 5B amounted to only $0.006 \pm 0.03 \mathrm{yr}^{-1}$. This mean was significantly $(\mathrm{p}<0.01, t$-test with $\mathrm{n}=32+32)$ smaller than the above mean difference of $0.07 \pm 0.04 \mathrm{yr}^{-1}$ between observed and Brey-calculated values of $P / B$. For single years, the differences between $Z$ and observed $P / B$ values (irrespective of the + or - sign) amounted to $0.13 \pm 0.02 \mathrm{yr}^{-1}(\mathrm{n}=32)$ or to $26 \pm 4 \%(\mathrm{n}=32)$ of the observed values. Both averages were significantly smaller than the corresponding means shown above for the differences between Brey-calculated and observed $P / B$ values of $0.18 \mathrm{yr}^{-1}$ and $35 \%$, respectively ( $t$-tests with $\mathrm{n}=32+32$ ). Thus annual $Z$ values predicted annual $P / B$ values more precisely than the annual $W$ values used in the Brey model calculations. Moreover, differences between $Z$ and $P / B$ were not significantly related to $Z$ (Fig. 5B: the best linear fit did not significantly deviate from a horizontal line through the zero-difference point).

\section{$P / B$ values in other Macoma balthica populations}

From the literature, data sets are available on mean individual weights, annual rates of mortality and assessments of $P / B$ in many populations of several species. Brey $(1990,2001)$ used such data sets to establish an empirical relationship between $W$ and $P / B$. We selected the 4 on Macoma balthica that included data on $Z$ or allowed an estimate of $Z$ (in addition to explicitly stated data on $W$ and $P / B$ ).

A plot of the differences between observed and Brey-predicted $P / B$ values against annual $Z$ (Fig. 5C) shows a satisfactory model prediction in 2 cases: $\mathrm{Cr}$ and WP for data taken from Cranford et al. (1985) and Warwick \& Price (1975), respectively. The point for the long-term averages of the present study (Pr in Fig. 5C) fits closely as well. However, the Brey model substantially underestimated $P / B$ in 2 other cases: MJ and CM for data taken from Madsen \& Jensen (1987) and Chambers \& Milne (1975), respectively. As in the present study (Fig. 5A), the underestimates by the Brey model occurred at relatively high values of $Z$ (Fig. 5C).

\section{DISCUSSION}

\section{Secondary production}

Measurements of secondary production are fundamental and indispensable in any attempt to quantify ecosystem functioning, including organic matter cycling and energy flow (Wong et al. 2011, Dolbeth et al. 2012). $P$ can be estimated directly by the weightincrement summation method proposed by Winberg (1971): $P$ is the sum of growth increments of all individuals present in the population for at least part of the study period. Similar direct (and laborious) methods, such as the Allen plot and the removalsummation method, lead to basically identical results (Gillespie \& Benke 1979). As a consequence of some assumptions (e.g. on the course of the decline of numbers of cohort members between samplings), the precision of direct estimates is not perfect, but will be satisfactory in most cases (Cusson et al. 2006). Direct methods are relatively simple and straightforward if separate cohorts can be distinguished. They require detailed knowledge of the course of numbers and weights of individuals assigned to cohorts (Van der Meer et al. 2005). Because gathering this information is laborious, simplified methods that do not require direct information on growth and dynamics have been proposed. Among the numerous models proposed as a shortcut (listed in Dolbeth et al. 2012), the model proposed by Brey $(1990,2001)$ appears to be the most commonly used one. This model estimates $P / B$ from $W$ values of the members of the population at a certain point in time. For an estimate of $P$, only single simultaneous measurements of $W$ and $B$ are required, resulting in a significant saving of labor and allowing for assessments of $P$ over extensive areas at acceptable costs (e.g. Bolam et al. 2010).

\section{Characteristics of the Brey model}

The Brey model is empirical and was presented by Brey (1990) as such. Proposals for a theoretical basis appear to fail. Sprung (1993) argued that growth should depend on body size by a weight exponent of -0.25 (as do other physiological rates), but he admits that mortality rates would also affect $P / B$ and that there is no fixed relationship between growth and mortality. Roa \& Quinones (1998) argued that the relationship between $W$ and $P / B$ can be understood by growth following the von Bertalanffy growth equation, but they did not include the role of mortality. In a comment on that paper, Van der Meer (1998) showed that the reasoning by Roa \& Quinones (1998) is flawed. Brey (1990, 2001) obtained the relationship between $P / B$ and $W$ that is the core of his model by indiscriminately collating a large number of data on populations of many species, usually obtained from short $(1 \mathrm{yr})$ studies, followed by a calculation of the best linear 
fit of the relationship between $P / B$ and $W$ in logarithmic form.

The lack of a theoretical basis (compare Van der Meer 1998) combined with the origin of the best fit from an averaging procedure means that it has a serious limitation: there is only a small chance that the Brey model would exactly predict $P$ or $P / B$ for any specific population in a specific year. For Van der Meer et al. (2005) this was reason not to recommend the use of this model for separate species. At the first presentation of his model, Brey (1990) recognized the limitation and recommended the use of his model only for community estimates. If the model were used exclusively for estimating $P$ for entire communities comprising many species, each with a substantial share of total biomass, its limitation might not be too serious. However, in practice, total biomass of communities is often dominated by only one or a few species, making precision of total $P$ estimates strongly dependent on the correctness of the $P / B$ estimates in these few species.

\section{Tests of the Brey model}

As far as we are aware, the Brey model has never been thoroughly tested for an extensive (multi-station or multi-year) data set on any specific population. The availability of a long data series on numbers and weights of members of cohorts in a population of Macoma balthica enabled us to estimate a set of values of $P$ and $P / B$ both directly by the weight-increment summation method for decades and by the Brey $(1990,2001)$ model. In this way, we could compare the outcomes for the same years of the 2 procedures, thus allowing an evaluation of the precision of estimates by the Brey (2001) model. Moreover, this exercise improved our insight into the basis of this model: though the basic relationship of the model between $W$ and $P / B$ is not obvious from a theoretical point of view, it proved to be fairly strong ( $r=-0.59$ for the log-log correlation) and statistically significant ( $p<0.001$; Fig. 4). Similar negative relationships between $W$ and $P / B$ were published by Sprung (1993) for cohorts of 3 species.

The basis of the crucial relationship between $W$ and $P / B$ can be argued and largely understood. In a balanced population, biomass remains constant and production of biomass, $P$, thus equals biomass lost by, for instance, predation: elimination, $E$. Thus, a higher $P / B$ means a higher $P / E$ and thus also a higher value of $Z$ (Allen 1971). Brey (1999, his Fig. 12) empirically confirmed the linear relationship $P / B$
$=Z$ for a multi-species assemblage (compare also our Fig. 2A for a multi-year confirmation in 1 species). The explanation for the observed relationship between $W$ and $P / B$ is that at high values of $Z$, few individuals reach a high age and thus a high weight. Consequently, values of $W$ are low at high values of $Z$ (compare Fig. 2B) and $P / B$ (as evidenced by Brey for a multi-species data set and in the present paper for a multi-year data set in 1 species in Fig. 4). Without offering a real theoretical basis, this reasoning nevertheless underpins the Brey model and was empirically shown by statistically significant relationships (Figs. $2 \& 4$ ).

The above reasoning does not offer a complete theoretical basis for the Brey relationship between $W$ and $P / B$, because it does not include any variability in growth rates (between species or years) at the same rate of mortality. If there were variability in growth rates at similar values of $Z$, a more rapid growth would result in a higher value of $W$ at the same value of $P / E(=Z)$ and of $P / B$ (in balanced populations). Thus, variation in growth rates can result in variation in $W$ (and consequently variation in Brey estimates of $P / B$ ) at the same real value of $P / B$. This means that the $P / B$ values from the Brey model (which are in essence multi-species averages) are correct in any specific population only if in this population the values of $W$ are related to $P / B$ (and thus $Z$ ) in the same way as the multi-species averages on which the model is based. For the Balgzand population of Macoma balthica, this was the case only in years with intermediate levels of mortality (Figs. 4 \& $5 \mathrm{~A})$. In the few years with extraordinarily high $Z$, the $W$-based Brey estimates were underestimates of $P / B$ (the open points in Fig. 4 were all situated above the Brey line), whereas they were underestimates in nearly all other years. The more extreme the $Z$ value was in a given year, the higher was the deviation of the Brey estimate of $P / B$ from the real one (Fig. 5A).

An important outcome of the present study is that the long-term mean of annual $P / B$ values predicted from the Brey model hardly differed from that of observed $P / B$ values: in Fig. $5 C$, the point indicated Pr is situated close to the dotted zero-difference line. Thus, not only an averaging procedure of $W$ and $P / B$ for several species (as conducted by Brey), but also averaging estimates for many years in only one species produced an acceptable (long-term) estimate of $P$ in a single species.

The above conclusion should be put in perspective. The Brey model performed less satisfactorily for individual years: deviations of model-calculated from 
observed $P / B$ values amounted to an average of $35 \%$ of the observed values, and in a quarter of the years they exceeded $50 \%$ of the observed values. The deviations from observed values were negligible only in the years when $Z$ was between 0.4 and $0.6 \mathrm{yr}^{-1}$ (Fig. 5A). The Brey model overestimated $P / B$ in most of the years (Fig. 4). Only because of the occurrence of a restricted $(7 \mathrm{yr})$ period of enhanced mortality rates within the total $33 \mathrm{yr}$ period of observation were the above-mentioned long-term means of model-predicted and observed $P / B$ values rather close, differing by only $\sim 10 \%$ of the mean of observed values. Anyway, the long-term average of annual $Z$ values in the studied population differed by only $1 \%$ from the long-term average of observed $P / B$. Estimates of $Z$ would allow more precise estimates of $P / B$ than those of $W$, in accordance with theory (see above).

Circumstances contributing to a satisfactory estimate of $P / B$ and $P$ by the $W$-based Brey model in the Macoma balthica populations may include:

(1) Though the $M$. balthica population was not really constant or balanced (Fig. 1), the rate of change of biomass over the entire 33 yr period was limited to only about $0.1 \mathrm{~g} \mathrm{yr}^{-1}$ - only a few percent of the long-term average biomass of $\sim 3 \mathrm{~g} \mathrm{~m}^{-2}$ (Fig. 1B). This relatively low rate of long-term change explains why the long-term mean of estimates of $P / B$ that were based on $Z$ were almost identical to the long-term mean of observed $P / B$ values (which were based on the weight-increment summation method): because the long-term mean of $P / B$ of the population was close to that of $P / E$ and $P / E=Z$.

(2) The Balgzand M. balthica population showed a significant correlation between the observed annual values of $Z$ and $W$ (Fig. 2B). Then, not only annual values of $Z$ are expected to provide a fair prediction of annual $P / B$ (as shown in Fig. 2A), but also annual values of $W$ should do (and did: Fig. 4). Note in Fig. 2A that the linear best fit of the relationship between $P / B$ and $Z$ was close to the 1:1 line and that the scatter of the separate annual points was rather limited. The reason why the Brey model worked satisfactorily might be that the variability in $W$ was largely founded on variability in $Z$ (and not on variability in growth rates), which largely determines variability in $P / B$.

In practice, an awkward problem with the use of the Brey model may be that its outcome changes with the season of data collection. In the course of a growing season, individual mean weights of cohort members increase and Brey model estimates of $P / B$ are then bound to decline. Usually, the resulting decline of annual $P(=B \times P / B)$ estimates will be compensated more or less by a biomass increase in the growing season. In the Balgzand population of Macoma balth$i c a$, seasonal increases of $B$ were found to over-compensate for the seasonal declines of model estimates of $P / B$. This resulted in much higher (on average by $38 \%$ ) model estimates of annual $P$ values when August rather than March observations of $W$ and $B$ were used (Fig. 3A). Thus, the sampling season matters for Brey-model-based estimates of $P$, which are intended to be estimates of annual production. The long-term means of model estimates that were based on March data (as contrasted to August data) were close to long-term means of observed annual values. Thus, for Brey estimates of $P$ for the Balgzand population, the use of March (or of annual) sampling data of $W$ and $B$ is preferable.

So far, the Brey model has been evaluated only for communities with 5 or more constituent species. Brey (1990) as well as Dolbeth et al. (2005) showed 4 comparisons between model-estimated and observed $P$ values. In 7 of these 8 cases, the deviations were acceptable $(<\sim 10 \%$ of the observed values). In individual species, however, unsatisfactorily high deviations (estimates that were either more than double or less than half of the observed values) were frequent: in 17 of the 50 cases. In the present study, we found such substantial deviations in 5 of 66 cases (Fig. 3B). Brey (1990) thus rightly recommended using his model only for communities with a sufficiently high number of species (he suggested at least 5) that are not dominated by a species with an extraordinarily high share of the total biomass (such as mussel beds).

\section{Conclusions}

The present study yields more conclusions that are relevant for an understanding of the Brey (2001) model and its constraints when applied to a single species:

(1) We found a rough corroboration of the negative logarithmic relationship between $P / B$ ratio values and $W$ (mean weights of the individuals in the population) on which the model is based (Fig. 4) and conclude that (in Macoma balthica) the model is sound.

(2) In the Brey model, any $W$ value corresponds with a $P / B$ estimate that represents an average of (mostly 1 yr) estimates for a high number of populations of different species. Whether such a $P / B$ estimate is correct in any particular population of 1 species would depend on the magnitude of the annual mortality for the particular population (Fig. 5). 
(3) In the Brey model (and in any model that derives $P / B$ exclusively from body weight) a term that accounts for variation in mortality is lacking. This lack explains a substantial part of the reported deviations of Brey estimates from observed $P / B$ values (Fig. 5A): at high mortality, the Brey model yields underestimates of $P / B$, whereas in periods (or species) characterized by relatively low mortality, Brey estimates will be positively biased.

(4) Direct measurements of annual $Z$ would yield better (non-biased and more accurate) estimates of $P / B$ (Fig. 2A) than $W$ (Fig. 4). Thus, repeated samplings that yield a series of $Z$ estimates are preferable to those that yield measurements of only $W$. In Macoma balthica, the relationship between $W$ and $Z$ proved to be rather loose (Fig. 2B).

(5) Averaged over a period of decades, the longterm mean of model estimates of $P$ for the population of Macoma balthica was close to the mean of directly observed $P$ values. Therefore, the model may be used for individual species if measurements of $W$ are available for a large number of years (with sufficient variability of $Z$ ).

(6) However, there is a restriction to the above conclusion: this was the case only when model calculations were based on data collected in late winter (at minimal values of $B$ ). Summer data (with much higher $B$ ) yielded substantial overestimates of $P$ in most years (Fig. 3). If this were the case in all or most species, an adaptation of the use of the Brey model (which is based on annual estimates) would be needed to account for the influence of season on $B$ and $W$. Such an adaptation (requiring assessments of annual values of $B$ and $W$ ) would undo an important advantage of the use of the Brey model, as it would require a much higher sampling effort.

Acknowledgements. We are grateful to T. Brey (AWI, Bremerhaven) and J. van der Meer (NIOZ, Texel) for fruitful discussions. Comments by 3 reviewers were helpful in clarification of our formulations.

\section{LITERATURE CITED}

Allen KR (1971) Relation between production and biomass. J Fish Res Board Can 28:1573-1581

> Banse K, Mosher S (1980) Adult body mass and annual production/biomass relationships of field populations. Ecol Monogr 50:355-379

Beukema JJ (1989) Molluscan life spans and long-term cycles in benthic communities. Oecologia 80:570

Beukema JJ (1997) Caloric values of marine invertebrates with an emphasis on the soft parts of marine bivalves. Oceanogr Mar Biol Annu Rev 35:387-414
Beukema JJ, Cadée GC (1997) Local differences on macrozoobenthic response to enhanced food supply caused by mild eutrophication in a Wadden Sea area: food is only locally a limiting factor. Limnol Oceanogr 42:1424-1435

> Beukema JJ, Dekker R, Jansen JM (2009) Some like it cold: populations of the tellinid bivalve Macoma balthica (L.) suffer in various ways from a warming climate. Mar Ecol Prog Ser 384:135-145

> Bolam SG, Barrio-Frojan CRS, Eggleton JD (2010) Macrofaunal production along the UK continental shelf. J Sea Res 64:166-179

Bolam SG, Barry J, Bolam T, Mason C, Rumney HS, Thain JE, Law RJ (2011) Impacts of maintenance dredged material disposal on macrobenthic structure and secondary productivity. Mar Pollut Bull 62:2230-2245

Brey $\mathrm{T}$ (1990) Estimating productivity of macrobenthic invertebrates from biomass and mean individual weight. Meeresforsch 32:329-343

Brey T (1999) Growth performance and mortality in aquatic macrobenthic invertebrates. Adv Mar Biol 35:153-223

Brey T (2001) Population dynamics in benthic invertebrates: a virtual handbook, Version 4-04. Alfred Wegener Institute, Bremerhaven, available at www.thomas-brey.de/ science/virtualhandbook (accessed 2011)

- Brey T (2012) A multi-parameter artificial neural network model to estimate macrobenthic invertebrate productivity and production. Limnol Oceanogr Methods 10: 581-589

Brey T, Jarre-Teichmann A, Borlich O (1996) Artificial neural network versus multiple linear regression: predicting $P / B$ ratios from empirical data. Mar Ecol Prog Ser 140:251-256

> Chambers MR, Milne H (1975) The production of Macoma balthica (L.) in the Ythan estuary. Estuar Coast Mar Sci 3: 443-455

Cranford PJ, Peer DL, Gordon DC (1985) Population dynamics and production of Macoma balthica in Cumberland Basin and Shepody Bay, Bay of Fundy. Neth J Sea Res 19: 135-146

Cusson M, Bourget E (2005) Global patterns of macroinvertebrate production in marine benthic habitats. Mar Ecol Prog Ser 297:1-14

> Cusson M, Plante JF, Genest C (2006) Effect of different sampling designs and methods on the estimation of secondary production: a simulation. Limnol Oceanogr Methods 4:38-48

> Dekker R, Beukema JJ (2007) Long-term and large-scale variability in productivity of the tellinid bivalve Macoma balthica on Wadden Sea tidal flats. Mar Ecol Prog Ser 337:117-134

> Dolbeth M, Lillebø AI, Cardoso PG, Ferreira SM, Pardal MA (2005) Annual production of estuarine fauna in different environmental conditions: an evaluation of the estimation methods. J Exp Mar Biol Ecol 326:115-127

> Dolbeth M, Cusson M, Sousa R, Pardal MA (2012) Secondary production as a tool for better understanding of aquatic ecosystems. Can J Fish Aquat Sci 69:1230-1253

Gillespie DM, Benke AC (1979) Methods of calculating cohort production from field data: some relationships. Limnol Oceanogr 24:171-176

Kedra M, Renaud PE, Andrade H, Goszczko I, Ambrose WG Jr. (2013) Benthic community structure, diversity, and productivity in the shallow Barents Sea bank (Svalbard Bank). Mar Biol 160:805-819, doi:10.1007/s00227-0122135-y 
Lammens JJ (1967) Growth and reproduction of a tidal flat population of Macoma balthica (L.). Neth J Sea Res 3: 315-382

Madsen PB, Jensen K (1987) Population dynamics of Macoma balthica in the Danish Wadden Sea in an organically enriched area. Ophelia 27:197-208

Mistri M, Fano EA, Rossi R (2001) Macrofaunal secondary production in a lagoon of the Po River Delta: an evaluation of estimation methods. Ital J Zool 68:147-151

Neumann H, Reiss H, Rakers S, Ehrich S, Kröncke I (2009) Temporal variability in southern North Sea epifauna communities after the cold winter of 1995/1996. ICES J Mar Sci 66:2233-2243

Petracco M, Cardoso RS, Corbisier TN, Turra A (2012) Secondary production of sandy beach macrofauna: an evaluation of predictive models. Estuar Coast Shelf Sci 115: 359-365

Reiss H, Greenstreet SPR, Sieben K, Ehrich S and others (2009) Effects of fishing disturbance on benthic communities and secondary production within an intensively fished area. Mar Ecol Prog Ser 394:201-213

Roa R, Quiñones RA (1998) Theoretical analysis of the relationship between production per unit biomass and animal body size. Oikos 81:161-167

Robertson AI (1979) The relationship between annual production: biomass ratios and lifespans for marine macrobenthos. Oecologia 38:193-202

Schwinghamer P, Hargrave B, Peer D, Hawkins CM (1986)

Editorial responsibility: Robert Stead,

Puerto Montt, Chile
Partitioning of production and respiration among size groups of organisms in an intertidal benthic community. Mar Ecol Prog Ser 31:131-142

Sprung M (1993) Estimating macrobenthic secondary production from body weight and biomass: a field test in a non-boreal intertidal habitat. Mar Ecol Prog Ser 100: 103-109

Tumbiolo ML, Downing JA (1994) An empirical model for the prediction of secondary production in marine benthic invertebrate populations. Mar Ecol Prog Ser 114:165-174

Van Aken HM (2008) Variability of the water temperature in the western Wadden Sea on tidal to centennial time scales. J Sea Res 60:227-234

Van der Meer J (1998) Theoretical analysis of the relationship between production per unit biomass and animal body size: a comment. Oikos 83:331-332

Van der Meer J, Heip CH, Herman PJM, Moens T, Van Oevelen D (2005) Measuring the flow of energy and matter in marine benthic animal populations. In: Eleftheriou A, McIntyre A (eds) Methods for the study of marine benthos, 3rd edn. Blackwell Science, Oxford, p 326-407

> Warwick RM, Price R (1975) Macrofauna production in an estuarine mud-flat. J Mar Biol Assoc UK 55:1-18

Winberg GG (1971) Methods for estimation of production in aquatic animals. Academic Press, London

> Wong MC, Peterson CH, Piehler MF (2011) Evaluating estuarine habitats using secondary production as a proxy for food web support. Mar Ecol Prog Ser 440:11-25

Submitted: October 29, 2012; Accepted: May 15, 2013

Proofs received from author(s): August 19, 2013 